\title{
Larvas de Chironomidae ( Diptera) em depósitos de folhiço submerso em um riacho de primeira ordem da Mata Atlântica (Rio de Janeiro, Brasil)
}

\author{
Angela M. Sanseverino ${ }^{1}$ \& Jorge Luiz Nessimian ${ }^{1}$
} ${ }^{1}$ Laboratório de Entomologia, Departamento de Zoologia, Instituto de Biologia, UFRJ, Caixa Postal 68044, 21944-970, Rio de Janeiro-RJ, Brasil.
amsansev@biologia.ufrj.br, nessimia@acd.ufrj.br

\begin{abstract}
Chironomidae larvae (Diptera) in submerged litter accumulations in a first order stream of the Atlantic Forest (Rio de Janeiro, Brazil). We investigated the fauna of larval Chironomidae in accumulations of submerged organic matter (litter) in a first-order stream in the mountain region (about $1000 \mathrm{~m}$ a.s.1.) of Rio de Janeiro state. The Chironomidae fauna of submerged litter was quantitatively sampled during autumn, winter, spring and summer. Litter fragmentation was estimated and the presence of leaves, wood, roots and fruits was investigated. Variations in the chironomid fauna composition and litter structure were studied, and hypotheses about factors influencing chironomid in these litter accumulations were proposed. The subfamilies Chironominae, Orthocladiinae and Tanypodinae were present and frequency participation of each subfamily and genus was calculated for each season. The Chironominae and Orthocladiinae were identified to genus level, and a total of 23 genera were found. Lauterborniella, Polypedilum and Tanytarsus were the most abundant genera. We observed a variation in the submerged litter structure among seasons, which is probably influenced by geological and climatic factors (mainly precipitation) affecting the drainage basin. The structure of the chironomid fauna changed during the studied period, with genera varying in participation and occurrence among the four seasons. Climatic effects on riparian vegetation and on stream physical characteristics were discussed in order to elucidate their influence on submerged litter accumulations and the chironomid fauna structure.
\end{abstract}

KEYWORDS. Aquatic insects; substrate; stream ecology; tropical forest.

RESUMO. Larvas de Chironomidae (Diptera) em depósitos de folhiço submerso em um riacho de primeira ordem da Mata Atlântica (Rio de Janeiro, Brasil). Neste estudo investigamos a fauna de larvas de Chironomidae presente em depósitos submersos de matéria orgânica (folhiço) em um riacho de primeira ordem na região serrana (cerca de $1100 \mathrm{~m}$ ) do Estado do Rio de Janeiro. A fauna de Chironomidae do folhiço submerso foi quantitativamente amostrada durante o outono, inverno, primavera e verão. A fragmentação do folhiço foi estimada e a presença de folhas, madeira, raízes e frutos foi investigada. Foram estudadas variações na composição da fauna e na estrutura do folhiço entre as estações do ano e levantadas hipóteses acerca de possíveis fatores que influenciariam os quironomídeos nestes depósitos de folhiço. As subfamílias Chironominae, Orthocladiinae e Tanypodinae foram encontradas e as participações de freqüência de cada subfamília e gênero calculadas em cada estação. Chironominae e Orthocladiinae foram identificados até o nível genérico, e 23 gêneros foram encontrados. Lauterborniella, Polypedilum e Tanytarsus foram os gêneros mais abundantes. Foi observada uma variação na estrutura do folhiço submerso entre as estações do ano, sendo provavelmente influenciada pelas interações entre fatores climáticos (principalmente precipitações) e o relevo e seus efeitos na bacia de drenagem. A fauna de Chironomidae também apresentou mudanças durante o período estudado, com grupos variando quanto à participação relativa e quanto à ocorrência entre as estações. Os efeitos do clima na vegetação e nas características físicas do riacho foram discutidos para elucidar suas influências nos depósitos de folhiço e na fauna de Chironomidae.

PALAVRAS-CHAVE. Insetos aquáticos; substrato; ecologia de rios; floresta tropical.

Entre os invertebrados aquáticos, a família Chironomidae é um dos mais abundantes e ricos grupos de organismos encontrados em riachos. Os representantes dessa família ocorrem em quase todos os ambientes de água doce, vivendo em sistemas lóticos e lênticos, incluindo fontes termais, lagos vulcânicos, águas doces de degelo, acúmulos de água em folhas e madeiras, solo úmido, águas salobras e zona intertidal de marés (Pinder 1995). O gênero de Chironomidae, Pontomyia, pode ser considerado verdadeiramente marinho (Cheng \& Collins 1980). Em ambientes lóticos, larvas de quironomídeos podem ser encontradas em quase todos os substratos, habitando acúmulos de folhiço, pedras, seixos, cascalho, areia, musgos, hidrófitas vasculares, etc.

Muitos sistemas de cabeceiras são fortemente influenciados pela vegetação circundante, a qual reduz a produção autotrófica devido ao sombreamento e contribui com grandes quantidades de detrito alóctone. Esses sistemas mostram uma interface máxima com a paisagem e são, desta forma, predominantemente acumuladores, processadores e transportadores de materiais provenientes do ambiente terrestre (Vanotte et al. 1980).

A matéria orgânica morta é a principal via de carbono na maioria dos ecossistemas: 70 a $90 \%$ de toda a produção primária entram na cadeia trófica de detritos (Wallace et al. 1997). Em ambientes com baixa produção primária como as cabeceiras de um rio, a biota é sustentada pela entrada de matéria orgânica alóctone. Bilby \& Likens (1980) mencionam que, em riachos de primeira ordem, cerca de 75\% do "standing stock" de matéria orgânica está contido nos depósitos de detritos.

Walker (1992) indica que o folhiço submerso com seus 
decompositores não se constitui apenas na primeira ligação nas cadeias alimentares, mas também é o nicho de proteção e abrigo para os consumidores maiores. Os depósitos de folhiço também aumentam a área de fundo a ser colonizada em riachos, contribuindo para o mosaico dinâmico de tipos de hábitat (Ward 1992). Muitos macroinvertebrados de água doce consomem diretamente o folhiço e/ou sua microfauna associada. De acordo com Graça (2001), a decomposição desse material orgânico é um processo contínuo que envolve fatores bióticos (decompositores e detritívoros) e abióticos (abrasão física). As cadeias tróficas aquáticas começam, basicamente, com a decomposição do folhiço submerso por fungos aquáticos e com a ingestão desses fungos pela mesofauna bentônica que coloniza este hábitat (Walker 1987).

Os depósitos de folhiço em leitos de rios e riachos consistem de folhas, madeira, sementes, frutos, variando no estado de fragmentação. Muitas larvas de quironomídeos se alimentam dessa grande variedade de detritos e são classificadas de acordo com o que se alimentam (Coffman \& Ferrington 1984, 1996): partículas maiores de detritos (cortadores), partículas finas depositadas ou aderidas ao substrato (coletores-catadores e raspadores) e partículas finas de detritos em suspensão (coletores-filtradores).

O folhiço pode entrar nos riachos pela queda direta ou por movimentos laterais (Benfield 1997). Em zonas de florestas temperadas, a queda de folhiço e a entrada são sazonais (Pozo et al. 1997), mas nas florestas úmidas tropicais a queda de folhiço não é sincrônica e as folhas entram nos riachos ao longo de todo o ano (Benfield 1997). O folhiço fragmentado difere do folhiço mais inteiro no estado de decomposição e, desta forma, no conteúdo nutricional (Kobayashi \& Kagaya 2002). A estrutura e a fragmentação da matéria orgânica alóctone podem variar entre as diferentes áreas de depósito de um mesmo rio e, também, ao longo das estações do ano. $\mathrm{O}$ tempo de retenção desses bolsões de folhiço é influenciado, dentre outros fatores, por condições hidrológicas e climáticas. Desta forma, a retenção do folhiço irá determinar a abundância e a distribuição de macroinvertebrados (Wallace et al. 1997; Wallace et al. 1999).

O tamanho e a heterogeneidade dos substratos são parâmetros importantes no estudo de padrões de colonização de insetos aquáticos e de preferências específicas de microhábitat (Rae 2004). Substratos fisicamente complexos como folhas, madeira, hidrófitas e musgos, geralmente possuem mais táxons do que substratos estruturalmente mais simples como areia e leito rochoso (Vinson \& Hawkins 1998). Em comparação com outros substratos, os acúmulos de folhiço em riachos de áreas de florestas parecem ser o hábitat preferencialmente ocupado por larvas de Chironomidae (Sanseverino \& Nessimian 1998, 2001).

O objetivo deste trabalho é investigar a fauna de Chironomidae presente em depósitos de folhiço em um riacho de primeira ordem na região serrana do Estado do Rio de Janeiro. A composição da fauna de Chironomidae nesse substrato foi estudada ao longo das quatro estações do ano, buscando entender como fatores ambientais influenciam sua estrutura.

\section{MATERIAL E MÉTODOS}

O estudo foi desenvolvido em um trecho da seção ritral de um tributário de primeira ordem do Rio Paquequer, localizado no município de Teresópolis, Rio de Janeiro, em uma área de Mata Atlântica (Serra do Mar, cerca de $1100 \mathrm{~m}$ de altitude). O leito do riacho é principalmente constituído de pedras, seixos, cascalho e areia, sendo sua profundidade máxima em torno de $50 \mathrm{~cm}$. A cobertura vegetal é primariamente de floresta pluvial bastante preservada. $\mathrm{O}$ folhiço oriundo da vegetação ripária ocorre em áreas de erosão (retido entre pedras) e de depósito (em poções e áreas de remanso).

Neste estudo foi coletado o folhiço acumulado em áreas de depósito. O termo "folhiço" é aqui utilizado para a matéria orgânica depositada no fundo do riacho, composta por folhas, galhos, frutos, sementes, etc. Cinco amostras de folhiço submerso para cada estação do ano foram coletadas com o auxílio de puçás durante os meses de abril, julho e outubro de 1991 e fevereiro de 1992. No laboratório, o material foi lavado em peneiras de $290 \mu \mathrm{m}$, o substrato foi acondicionado em sacos plásticos para secagem e pesagem, e a fauna foi conservada em álcool etílico a $80 \%$. O material foi triado sob estereomicroscópio e, para identificação, as larvas foram montadas em lâminas permanentes para microscopia óptica, usando Euparal como meio de montagem. A identificação dos gêneros foi realizada com o auxílio das chaves taxonômicas de Cranston et al. (1983), Pinder \& Reiss (1983), Epler (1995) e Trivinho-Strixino \& Strixino (1995). Um total de 23 gêneros pertencentes às subfamílias Chironominae e Orthocladiinae foi estudado. As larvas de Tanypodinae não foram identificadas, porém foram incluídas nas análises.

As abreviaturas latinas aff. (affinis) e $c f$. (confer) foram usadas, respectivamente, quando o gênero não era possível de ser identificado, sendo, porém, próximo de um gênero já descrito e conhecido (aff. Nilothauma, aff. Tribelos, aff. Georthocladius, aff. Mesosmittia, e aff. Pseudosmittia) e quando o gênero pôde ser identificado, porém necessitando comparação com material-tipo (cf. Paratendipes). O táxon "Chironomini tipo 26" representa um novo gênero ainda não descrito, identificado, registrado e depositado como "tipo 26" na coleção entomológica do Museu de Zoologia de Munique (Alemanha).

Em cada período de coleta foram feitas medições de vazão, temperatura do ar e da água, $\mathrm{pH}$ (pHmetro portátil), condutividade elétrica (condutivímetro portátil), oxigênio dissolvido (método de Winkler), nitrito e amônia. Para o cálculo da vazão foram medidas a velocidade da corrente e a área da seção transversal de um trecho fixo estabelecido no local de coleta, utilizando a fórmula "Vazão = área média da seção x velocidade da corrente". A velocidade foi obtida pelo método do flutuador. Para calcular a área foram feitas medidas da profundidade média e medida horizontal no fundo do riacho. As análises de oxigênio dissolvido (método de Winkler), nitrito e amônia foram feitas no Laboratório de Análises Ambientais do Departamento de Biologia Marinha, Universidade Federal do Rio de Janeiro. 
A estrutura do folhiço foi caracterizada quanto à composição e à fragmentação. Após a secagem, o substrato foi pesado em balança analítica, e a presença de folhas, madeira, raízes e frutos foi analisada. A quantidade de cada componente por amostra foi estimada através da ocupação destes itens em uma superfície plana marcada com campos (quadrantes) dentro de área de um metro quadrado. $\mathrm{O}$ valor de cada componente representa o número de parcelas $(5 \mathrm{~cm} \times 5 \mathrm{~cm})$ que o mesmo ocupou nesta área. A fragmentação foi obtida através do lançamento ao acaso (três vezes, obtendo-se uma média) de transeções colocadas sobre o bolsão de folhiço. Em cada transeção, fez-se a contagem dos fragmentos interceptados pelo mesmo. A densidade das larvas foi estimada através do número de indivíduos por peso seco (em gramas) das amostras em cada estação do ano.

Com o objetivo de investigar se ocorreu variação na composição do folhiço entre as estações do ano foi feita uma tabela de contingência - teste de distribuição Qui-quadrado $\left(X^{2}\right)$ para 9 graus de liberdade $(v=9)$ - com base nos componentes (folhas, madeira, raízes, frutos).

O mesmo teste foi aplicado para avaliar se houve variação significativa na estrutura da fauna de Chironomidae entre as estações do ano, baseando-se nos totais de larvas de cada grupo por estação. Aqui o teste foi realizado para 69 graus de liberdade $(v=69)$, e as probabilidades de ocorrência $(p)$ foram comparadas com um nível de significância de $0,001(\alpha=0,001)$.

Com o objetivo de descrever e interpretar relações dos táxons com o ambiente, foi feita uma Análise de Correspondência Canônica (CCA) usando o programa estatístico PC-ORD para Windows (McCune \& Mefford 1999). A CCA é um método de ordenação que foca nas relações entre as espécies e variáveis ambientais medidas, fornecendo uma interpretação direta dos eixos de ordenação (Ter Braak 1986). Esta análise é apropriada quando se tem por finalidade descrever variação de uma comunidade em relação a um grupo particular de variáveis ambientais (McCune 1997). Através desta análise, coeficientes canônicos são obtidos por regressão múltipla, cujo objetivo final é apontar a efetividade das variáveis ambientais em estruturar a ordenação e descrever as relações dessas variáveis com os eixos. Os dados dos táxons foram logaritmizados $(\log X+1)$ e os valores das variáveis ambientais foram transformados ((Valor X - Média) / Desvio Padrão) para serem usados na CCA. A matriz principal foi composta por 20 amostras e 18 táxons, enquanto que a matriz secundária foi formada por 20 amostras e 5 variáveis. As opções de análise selecionadas foram: 1-centralização e estandartização das coordenadas dos eixos a unidades de variância; 2-otimização das colunas; e 3- as coordenadas das amostras nos gráficos são combinações lineares das variáveis ("LC scores"). Cryptochironomus, Complexo Harnischia gênero 1, cf. Paratendipes, aff. Mesosmittia, aff. Pseudosmittia e Rheocricotopus tiveram ocorrências baixas nas amostras, com um único indivíduo, e desta forma não foram incluídos na análise. As variáveis ambientais selecionadas foram vazão, folhas, madeira, peso da matéria orgânica e fragmentação. As demais variáveis não foram incluídas na análise pois ou eram fortemente correlacionadas umas com as outras (variáveis físicas e químicas) ou foram tão raras (frutos e raízes) que, mesmo sofrendo uma transformação prévia, seus efeitos na composição da comunidade não poderiam ser separados e corretamente interpretados.

\section{RESULTADOS}

Estrutura do folhiço submerso. Os resultados da composição, fragmentação e peso dos depósitos de folhiço estão apresentados na Tabela I.

Com relação à composição, os principais componentes dos bolsões de folhiço são folhas e madeira, com predominância do primeiro item. Em menor quantidade são também encontrados frutos e raízes.

O resultado do teste de distribuição Qui-quadrado mostrou que houve variação significativa na composição do folhiço entre as estações do ano $\left(X^{2}=58,83 ; v=9 ; p<0,001\right)$. Uma maior quantidade de folhas foi encontrada na primavera, enquanto que a menor quantidade ocorreu no inverno. O componente madeira ocorreu em maior quantidade no inverno e em menor quantidade no verão. A presença de frutos no folhiço foi observada principalmente no outono, sendo que na primavera este item não foi encontrado. Para raízes, a maior quantidade ocorreu no inverno, sendo que a primavera e o verão não apresentaram este componente. A quantidade de folhiço foi maior na primavera e menor no outono.

O peso seco médio do folhiço foi maior no inverno $(71,85$ $\mathrm{g}$ ), enquanto que o menor peso foi encontrado no outono $(38,31 \mathrm{~g})$. Apesar de o inverno apresentar uma menor quantidade

Tabela I. Composição, peso seco e fragmentação das amostras de depósitos de folhiço, coletadas em um tributário de primeira ordem do Rio Paquequer (Teresópolis, RJ), durante o outono, inverno, primavera e verão. Out- Outono; Inv- Inverno; Prim- Primavera; Ver- Verão.

\begin{tabular}{ccccccc}
\hline Amostras & Folhas & Madeira & Raízes & Frutos & Peso $(\mathrm{g})$ & Fragmentação \\
\hline 1 Out & 6 & 0 & 0,5 & 0,25 & 7,27 & 7,84 \\
2 Out & 1 & 6 & 0 & 0,5 & 14,11 & 11,17 \\
3 Out & 33 & 5 & 0 & 0 & 101,69 & 21,67 \\
4 Out & 7 & 8 & 0 & 1 & 36,38 & 17,67 \\
5 Out & 2 & 9 & 0 & 1 & 32,12 & 9,0 \\
1 Inv & 6 & 0,5 & 0 & 0 & 4,8 & 11,34 \\
2 Inv & 4 & 2 & 0 & 0 & 23,38 & 31,34 \\
3 Inv & 1 & 8,5 & 0 & 0,25 & 17,71 & 11,34 \\
4 Inv & 9 & 30 & 2,25 & 0 & 235,88 & 9,67 \\
5 Inv & 15 & 10 & 0 & 0 & 77,51 & 12,34 \\
1 Prim & 9 & 1 & 0 & 0 & 9,2 & 12,0 \\
2 Prim & 72 & 4 & 0 & 0 & 105,15 & 16,5 \\
3 Prim & 4 & 20 & 0 & 0 & 77,34 & 9,0 \\
4 Prim & 30 & 4 & 0 & 0 & 36,44 & 9,0 \\
5 Prim & 11 & 5 & 0 & 0 & 70,03 & 14,0 \\
1 Ver & 9 & 6 & 0 & 0,25 & 66,09 & 9,0 \\
2 Ver & 30 & 5 & 0 & 0 & 57,49 & 11,67 \\
3 Ver & 43 & 8 & 0 & 1 & 10,36 & 23,67 \\
4 Ver & 16 & 0,5 & 0 & 0 & 19,5 & 21,0 \\
5 Ver & 6 & 4 & 0 & 0 & 62,78 & 21,34 \\
\hline
\end{tabular}


de folhas, este maior peso é atribuído ao componente madeira, observado em maior quantidade nesta estação.

Com relação à fragmentação do folhiço, o material apresentou-se mais fragmentado no verão e menos na primavera. Através de observações em campo pode-se notar a presença de folhas mais inteiras e um material menos particulado na primavera (folhiço "mais novo").

Variáveis ambientais. Os dados de temperatura do ar e variáveis físicas e químicas da água durante o período de estudos são encontrados na Tabela II. A vazão do riacho foi maior no outono $\left(0,0388 \mathrm{~m}^{3} / \mathrm{s}\right)$ e menor no inverno $\left(0,0055 \mathrm{~m}^{3} /\right.$ s). A temperatura do ar variou entre $24^{\circ} \mathrm{C}$ no outono e $18{ }^{\circ} \mathrm{C}$ no inverno. A temperatura da água também foi maior no outono $\left(20{ }^{\circ} \mathrm{C}\right)$ e menor no inverno $\left(15^{\circ} \mathrm{C}\right)$. Os valores de oxigênio dissolvido variaram entre $11,25 \mathrm{mg} / \mathrm{l}$ no outono e $7,76 \mathrm{mg} / \mathrm{l}$ no verão. $\mathrm{O} \mathrm{pH}$ da água ficou em torno de 5,3. A condutividade elétrica da água variou entre $21,3 \mu \mathrm{S} / \mathrm{cm}$ na primavera e 17,1 $\mu \mathrm{S} / \mathrm{cm}$ no outono. Os valores de nitrito não apresentaram diferença entre as estações e os valores de amônia foram menores no verão e no outono, e maiores na primavera.

Maio, junho, julho e agosto são considerados os meses mais secos. Durante as coletas no inverno não foram observadas chuvas, estando o nível de água do riacho mais baixo em relação às demais estações. Na primavera começam a ocorrer as primeiras chuvas, sendo que no verão acontecem as chamadas "chuvas torrenciais", carreando muito material do solo adjacente para dentro do riacho. No outono, apesar de não ser uma estação com pluviosidade alta, ocorreram chuvas fortes no período das coletas, tendo como conseqüência a alta vazão observada.

Estrutura da fauna de Chironomidae. Os dados de densidade de Chironomidae e o peso seco das amostras de folhiço podem ser observados na Tabela III. O outono mostrou a maior densidade de larvas (3,40 indivíduos/grama), enquanto que a menor densidade ocorreu no inverno (1,04 indivíduos/ grama).

Considerando a participação de cada subfamília no total coletado, Chironominae dominou com $72,89 \%$ das larvas, seguidos por Orthocladiinae (14,92\%) e Tanypodinae (12,19\%). Analisando a participação de cada subfamília por estação do

Tabela II. Variáveis físicas e químicas da água, medidas durante a coleta em cada estação do ano em um tributário de primeira ordem do Rio Paquequer (Teresópolis, RJ).

\begin{tabular}{lcccc}
\hline & Outono & Inverno & Primavera & Verão \\
\hline Vazão $\left(\mathrm{m}^{3} / \mathrm{s}\right)$ & 0,0388 & 0,0055 & 0,0132 & 0,0154 \\
Temperatura do ar $\left({ }^{\circ} \mathrm{C}\right)$ & 24 & 18 & 21 & 19,5 \\
Temperatura da água $\left({ }^{0} \mathrm{C}\right)$ & 20 & 15 & 16 & 17,5 \\
Oxigênio dissolvido $(\mathrm{mg} / \mathrm{l})$ & 11,25 & 9,75 & 8,23 & 7,76 \\
$\mathrm{pH}$ & 5,8 & 5,2 & 5,3 & 4,9 \\
Condutividade elétrica (ìS/cm $)$ & 17,1 & 20,3 & 21,3 & 18,2 \\
Nitrito (ìmol $\left./ \mathrm{dm}^{3}\right)$ & 0,5 & 0,5 & 0,5 & 0,5 \\
Amônia $\left(\mathrm{ìmol} / \mathrm{dm}^{3}\right)$ & 0,5 & 2,0 & 5,0 & 0,5 \\
\hline
\end{tabular}

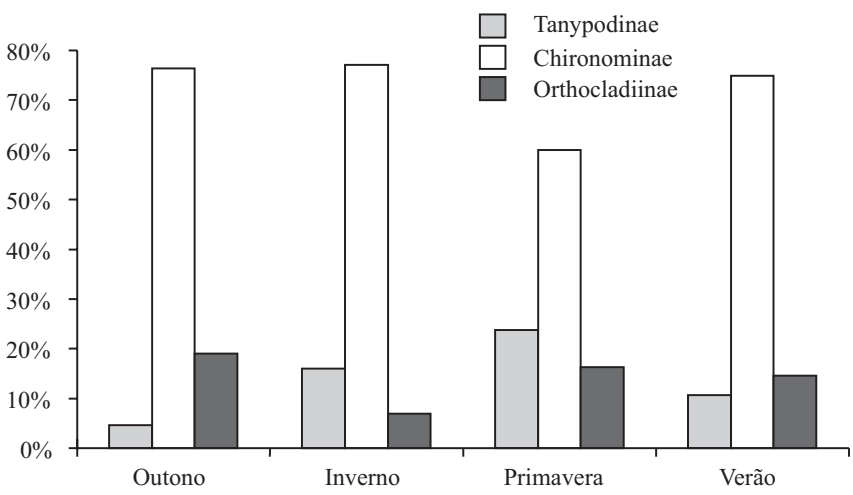

Fig. 1. Participação de cada subfamília de Chironomidae no total encontrado, por estação do ano, nas amostras de folhiço submerso em um tributário de primeira ordem do Rio Paquequer (Teresópolis, RJ).

ano (Fig. 1), Chironominae também foi dominante na composição, sendo que Orthocladiinae predominou sobre Tanypodinae durante o outono e o verão, e Tanypodinae sobre Orthocladiinae durante o inverno e a primavera.

O maior número de gêneros foi encontrado no outono (20), sendo 14 da subfamília Chironominae e 6 pertencendo à Orthocladiinae. No inverno ocorreram 19 gêneros (13 de Chironominae e 6 de Orthocladiinae). Na primavera foram coletados 17 gêneros, 12 dos quais Chironominae e 5 Orthocladiinae. $\mathrm{O}$ menor número de gêneros foi encontrado no verão (15), sendo 12 pertencentes à Chironominae e 5 à Orthocladiinae.

Considerando as subfamílias Chironominae e Orthocladiinae, foram encontrados 23 gêneros (Tab. IV), sendo que 12 estiveram presentes em todas as estações: Endotribelos, Lauterborniella, aff. Nilothauma, Oukuriella, Phaenopsectra, Polypedilum, Stenochironomus, Tanytarsus, aff. Tribelos, Chironominitipo 26, Corynoneura e Nanocladius. A maioria dos grupos encontrados foi considerada rara ou pouco comum, devido a pouca quantidade de larvas coletadas. Com relação a participação de cada gênero no total coletado nas amostras (Tab. IV), Lauterborniella apresentou o maior número de indivíduos, seguido por Tanytarsus e Polypedilum. Outros Chironominae também foram relativamente comuns, como Phaenopsectra e aff. Tribelos. Entre Orthocladiinae, os que apresentaram maior participação foram Corynoneura, Lopescladius e Nanocladius.

Os grupos minadores foram pouco comuns. Stenochironomus obteve a maior participação $(3,08 \%)$ na primavera e foi encontrado em todas as estações do ano,

Tabela III. Densidade das larvas de Chironomidae e peso das amostras de folhiço submerso por estação do ano, coletadas em um tributário de primeira ordem do Rio Paquequer (Teresópolis, RJ). ind/g- indivíduos por grama.

\begin{tabular}{lcccc}
\hline & Outono & Inverno & Primavera & Verão \\
\hline Densidade (ind/g) & 3,40 & 1,04 & 1,20 & 1,88 \\
Peso das Amostras (g) & 191,57 & 359,28 & 298,16 & 216,22 \\
\hline
\end{tabular}



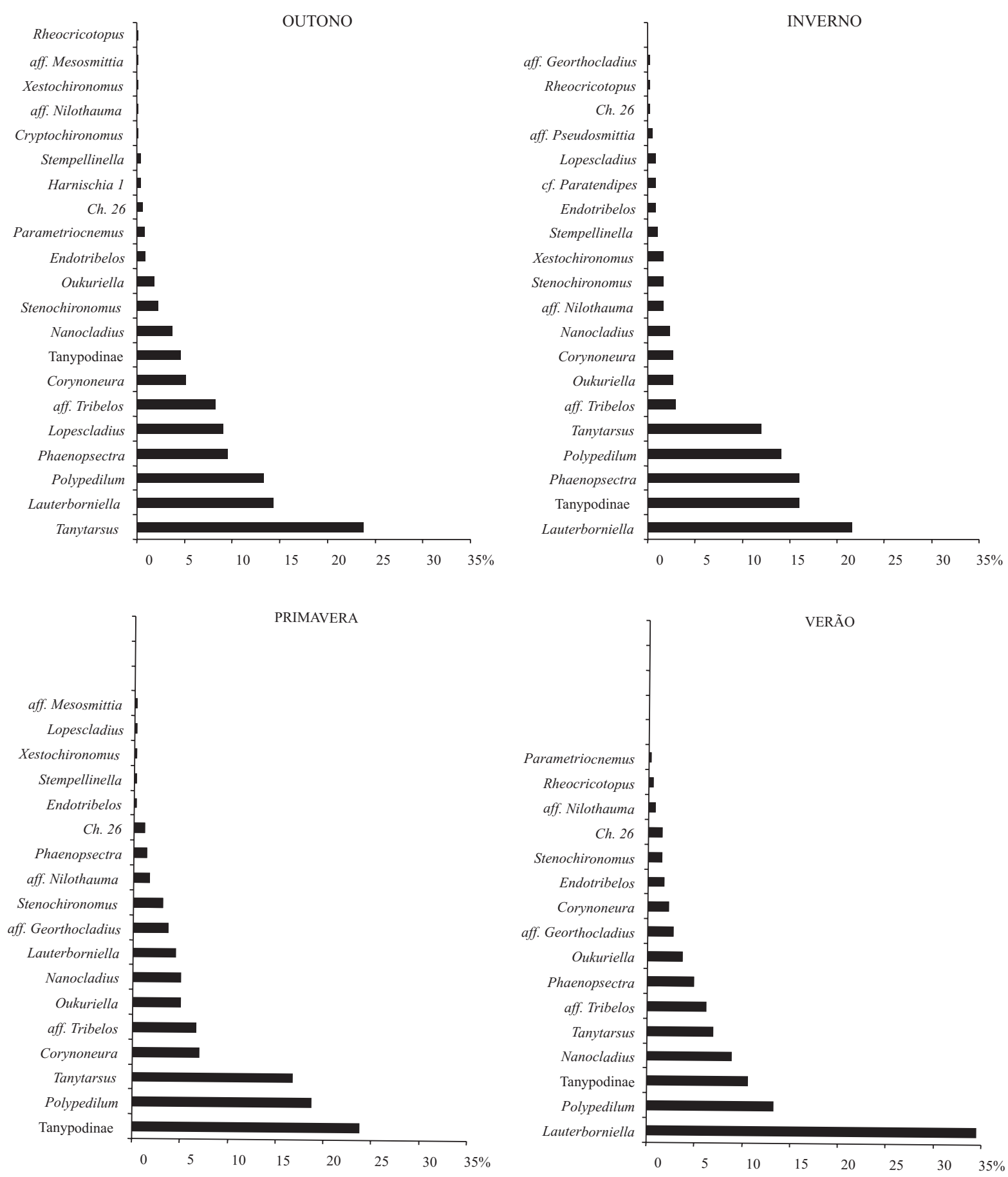

Fig. 2. Participação de cada gênero de Chironomidae no total encontrado para o outono, inverno, primavera e verão em amostras de folhiço submerso em áreas de depósito de um tributário de primeira ordem do Rio Paquequer (Teresópolis, RJ). Ch. 26, Chironomini tipo 26; Harnischia 1, Complexo Harnischia gênero 1.

enquanto que Xestochironomus apresentou a maior representatividade $(1,60 \%)$ no inverno, mas não foi encontrado durante o verão (Fig. 2).

$\mathrm{Na}$ composição da fauna de Chironomidae de outono, Tanypodinae participou com 4,6\%, sendo a menor participação encontrada entre as estações; Chironominae representou $76,3 \%$ e Orthocladiinae, $19,1 \%$ do total de larvas. A maior participação das larvas de Orthocladiinae na composição foi encontrada nesta estação do ano (Fig. 1). Tanytarsus foi o grupo dominante $(23,8 \%)$, seguido por Lauterborniella (14,3\%), Polypedilum (13,36\%), Phaenopsectra (9,5\%), Lopescladius $(9,1 \%)$ e aff. Tribelos $(8,3 \%)$. O número de larvas de Lopescladius encontrado no outono foi o maior, estando este grupo ausente no verão e em baixo número na primavera 
Tabela IV. Participação de freqüência de cada gênero de Chironomidae no total encontrado nas amostras de folhiço submerso em um tributário de primeira ordem do Rio Paquequer (Teresópolis, RJ). Em negrito estão assinalados os gêneros que mostraram as maiores abundâncias.

\begin{tabular}{|c|c|}
\hline Táxon & Porcentagem \\
\hline TANYPODINAE Thienemann \& Zavřel, 1916 & $12,19 \%$ \\
\hline CHIRONOMINAE Maquart, 1838 & $72,89 \%$ \\
\hline Cryptochironomus Kieffer, 1918 & $0,06 \%$ \\
\hline Endotribelos Grodhaus, 1987 & $0,95 \%$ \\
\hline Complexo Harnischia Kieffer, 1921 gênero 1 & $0,17 \%$ \\
\hline Lauterborniella Thienemann \& Bause, 1913 & $18,45 \%$ \\
\hline aff. Nilothauma Kieffer, 1921 & $0,89 \%$ \\
\hline Oukuriella Epler, 1986 & $3,07 \%$ \\
\hline cf. Paratendipes Kieffer, 1911 & $0,17 \%$ \\
\hline Phaenopsectra Kieffer, 1921 & $8,22 \%$ \\
\hline Polypedilum Kieffer, 1912 & $14,59 \%$ \\
\hline Stempellinella Brundin, 1947 & $0,45 \%$ \\
\hline Stenochironomus Kieffer, 1919 & $2,12 \%$ \\
\hline Tanytarsus van der Wulp, 1874 & $16,1 \%$ \\
\hline aff. Tribelos Townes, 1945 & $6,37 \%$ \\
\hline Xestochironomus Sublette \& Wirth, 1972 & $0,45 \%$ \\
\hline Chironomini tipo 26 & $0,84 \%$ \\
\hline ORTHOCLADIINAE Edwards, 1929 & $14,92 \%$ \\
\hline Corynoneura Winnertz, 1846 & $4,36 \%$ \\
\hline aff. Georthocladius Strenzke, 1941 & $1,4 \%$ \\
\hline Lopescladius Oliveira, 1967 & $3,52 \%$ \\
\hline aff. Mesosmittia Brundin, 1956 & $0,11 \%$ \\
\hline Nanocladius Kieffer,1913 & $4,85 \%$ \\
\hline Parametriocnemus Goetghebuer, 1932 & $0,34 \%$ \\
\hline aff. Pseudosmittia Goetghebuer, 1932 & $0,11 \%$ \\
\hline Rheocricotopus Thienemann \& Harnisch, 1932 & $0,22 \%$ \\
\hline
\end{tabular}

e no inverno. Dentre os grupos pouco comuns, Cryptochironomus e o complexo Harnischia gênero 1 só foram observados no folhiço neste período (Fig. 2).

No inverno (Figs. 1 e 2), Tanypodinae participou com $16,0 \%$, Chironominae representou $77,1 \%$ e Orthocladiinae, $6,9 \%$ do total de larvas. Comparando-se as estações, a maior participação de Chironominae na composição foi assinalada para esta estação, assim como a menor participação de Orthocladiinae. O gênero com maior participação no inverno foi Lauterborniella (21,6\%), seguido por Phaenopsectra (16,0\%), Polypedilum (14,1\%) e Tanytarsus (12,0\%). Os demais grupos estiveram presentes com poucos representantes e participação abaixo de 5,0\%.

Com relação à composição da fauna de Chironomidae na primavera (Figs. 1 e 2), Tanypodinae participou com $23,8 \%$, Chironominae representou 59,9\% e Orthocladiinae, 16,2\% do total de larvas. A primavera apresentou a maior participação de Tanypodinae na composição e a menor participação de Chironominae. Em três das estações ocorreu algum gênero com participação acima de $20 \%$, enquanto que na primavera os dois grupos de maior participação representaram, cada um, menos de $20 \%$ do total de larvas. Os grupos que predominaram na primavera foram Polypedilum e Tanytarsus com, respectivamente, $18,8 \%$ e $16,8 \%$. Lauterborniella, grupo que
Tabela V. Resultados da análise de correspondência canônica, para a fauna de Chironomidae de depósitos de folhiço submerso em um tributário de primeira ordem do Rio Paquequer (Teresópolis, RJ) e variáveis ambientais: autovalores dos eixos de ordenação, porcentagens (\%) explicadas e cumulativas da variância por eixo, e correlação de Pearson para os eixos, entre as espécies e o ambiente.

\begin{tabular}{lccc}
\hline & Eixo 1 & Eixo 2 & Eixo 3 \\
\hline Autovalor & 0,098 & 0,074 & 0,039 \\
\% explicada da variância & 14,4 & 10,9 & 5,7 \\
\% explicada cumulativa & 14,4 & 25,3 & 31,0 \\
Correlação espécies-ambiente & 0,904 & 0,781 & 0,765 \\
\hline
\end{tabular}

foi dominante no total de todas as amostras e que esteve entre os de maior participação por estação, na primavera representou apenas 4,5\%. Oukuriella apresentou a maior participação neste período $(5,0 \%)$, e o mesmo pode ser verificado para Corynoneura $(7,0 \%)$ e para os Orthocladiinae considerados "semi-terrestres" (3,6\%), um grupo próximo a Georthocladius.

No verão (Figs. 1 e 2), Tanypodinae participou com 10,6\%, Chironominae representou 74,9\% e Orthocladiinae, $14,5 \%$ do total de larvas. Lauterborniella foi quase exclusivamente o grupo predominante no verão, representando $34,5 \%$, sendo sua maior participação ao longo das estações. Polypedilum também foi relativamente importante neste período com $13,3 \%$ e Nanocladius apresentou sua maior participação (8,9\%).

A estrutura da comunidade de Chironomidae variou significativamente entre as estações do ano $\left(X^{2}=536,22 ; v=\right.$ 69; $p<0,001)$.

Na CCA(Tabs. V e VI), os três primeiros eixos de ordenação explicaram $31 \%$ da variância dos dados das espécies e a correlação espécies-ambiente foi alta nestes eixos (Tab. V). Os resultados obtidos através dos coeficientes (Tab. VI) mostraram que os componentes folhas e madeira foram as variáveis mais importantes no eixo 1, enquanto que a vazão foi mais importante no 2, e folhas, madeira, peso da matéria orgânica e fragmentação do folhiço no 3. O diagrama de ordenação da CCA para os eixos 1 e 2 é dado na Figura 3.

Tabela VI. Resultados da análise de correspondência canônica, para a fauna de Chironomidae de depósitos de folhiço submerso em um tributário de primeira ordem do Rio Paquequer (Teresópolis, RJ) e variáveis ambientais: coeficientes canônicos obtidos por regressão múltipla e coeficientes de correlação ("intraset correlations", Ter Braak 1986) entre as variáveis ambientais e os eixos de ordenação.

\begin{tabular}{lcccccc}
\hline & \multicolumn{3}{c}{$\begin{array}{c}\text { Coeficientes } \\
\text { Canônicos }\end{array}$} & \multicolumn{3}{c}{$\begin{array}{c}\text { Coeficientes de } \\
\text { Correlação }\end{array}$} \\
\hline Variável & Eixo 1 & Eixo 2 & Eixo 3 & Eixo 1 & Eixo 2 & Eixo 3 \\
\hline Vazão & $-0,176$ & 0,893 & 0,253 & $-0,403$ & 0,849 & 0,240 \\
Folhas & $-0,417$ & $-0,264$ & $-0,583$ & $-0,551$ & $-0,442$ & $-0,052$ \\
Madeira & 0,821 & 0,284 & $-0,863$ & 0,905 & $-0,007$ & $-0,027$ \\
Matéria & & & & & & \\
Orgânica & $-0,029$ & $-0,197$ & 1,294 & 0,543 & $-0,229$ & 0,465 \\
Fragmentação & 0,105 & $-0,239$ & 0,529 & $-0,267$ & $-0,345$ & 0,537
\end{tabular}




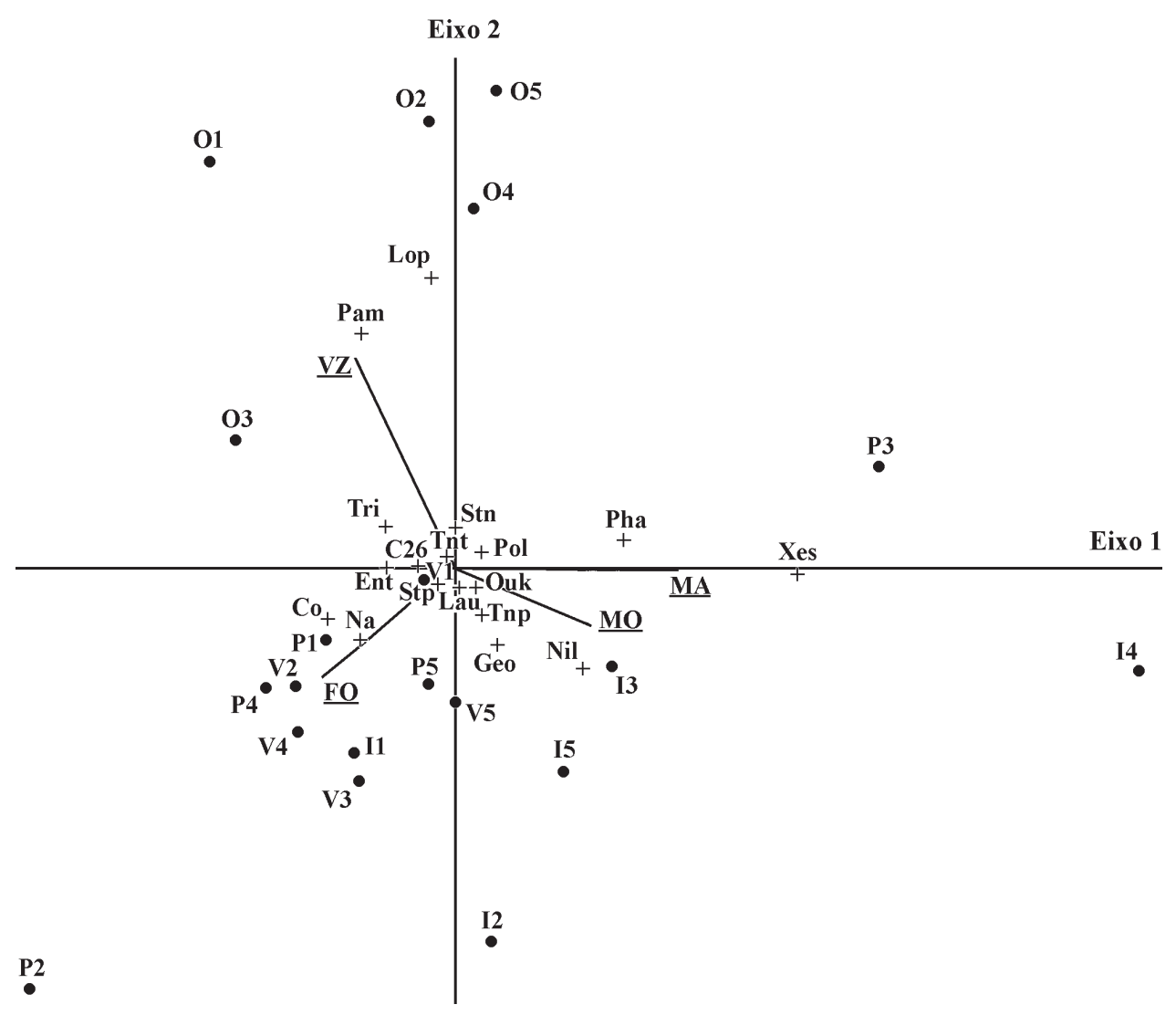

Fig. 3. Diagrama de ordenação de análise de correspondência canônica com amostras $(\bullet)$, táxons de Chironomidae $(+)$ e variáveis ambientais (setas), eixos 1 e 2. I1-I5- amostras de inverno; O1-O5- amostras de outono; P1-P5- amostras de primavera; V1-V5- amostras de verão; FOfolhas; MA- madeira; MO- peso da matéria orgânica; VZ- vazão; Co- Corynoneura; Ent- Endotribelos; Geo- aff. Georthocladius; LauLauterborniella; Lop- Lopescladius; Nan- Nanocladius; Nil- aff. Nilothauma; Ouk- Oukuriella; Pam- Parametriocnemus; Pha- Phaenopsectra; Pol- Polypedilum; Stp- Stempellinella; Stn, Stenochironomus; Tnp- Tanypodinae; Tnt- Tanytarsus; Tri- aff. Tribelos; Xes- Xestochironomus; C26- Chironomini tipo 26.

\section{DISCUSSÃO}

Em contraste com a floresta decídua temperada, com maior volume de queda de folhas no outono, a queda de folhas da vegetação de florestas tropicais é geralmente desprovida de uma periodicidade marcada, com uma entrada desta matéria orgânica nos riachos relativamente contínua ao longo do ano (Benfield 1997). As interações entre clima e geologia e seus efeitos na vegetação e nas características físicas da bacia de drenagem são os principais determinantes dos processos orgânicos nos riachos (Webster \& D'Angelo 1997). Geralmente o tempo de deposição e retenção do folhiço nestes ambientes aquáticos está associado à vazão e ao efeito de "lavagem" das chuvas, que fortemente influenciam sistemas de cabeceira.

No presente trabalho não foi avaliada a entrada de folhiço per se no ambiente aquático, porém o teste Qui-quadrado sugeriu que houve variação na estrutura deste entre as estações do ano.

Como já mencionado, o período considerado seco, quando são observadas as menores precipitações, abrange os meses de maio até agosto, sendo o inverno, a estação considerada seca, com a menor vazão. No inverno também se observou a menor quantidade de folhas, a maior quantidade de madeira e, conseqüentemente, o maior peso nas amostras. Dentre as estações, o inverno foi a única onde o predomínio foi do componente madeira e não de folhas. Uma explicação seria que a baixa correnteza neste período não teria força suficiente para carrear os componentes mais pesados dos depósitos de matéria orgânica como a madeira. Bilby \& Likens (1980) chamam atenção à importância das barragens naturais de detrito orgânico na estrutura e funcionamento dos sistemas de riachos. Segundo os autores, tais barragens são formadas quando um pedaço maior de madeira cai no riacho e se aloja atrás de pedras; pedaços menores de madeira vão sendo então retidos atrás deste pedaço maior, formando uma trama na qual folhas se acumulam.

$\mathrm{Na}$ primavera foi observada a maior quantidade total de componentes (folhas, madeira, etc.) e a menor fragmentação do material, o que significa a presença de folhas e demais itens mais inteiros, menos partidos. Na primavera são observadas na área as primeiras chuvas após a época seca, causando um carreamento rio abaixo do material que esteve retido no riacho durante este período de baixa precipitação. Além disso, estas chuvas estariam proporcionando uma maior entrada no riacho 
de folhiço pela queda de folhas e pelo próprio carreamento da matéria orgânica que esteve também, de certa forma, retida no solo durante este período mais seco.

No verão foi registrada a maior fragmentação e a menor quantidade de madeira nos bolsões de folhiço. $\mathrm{O}$ inverno também apresentou um material muito fragmentado, mas uma grande quantidade de madeira. No caso, estas maiores fragmentações podem ser indicativas de duas diferentes causas. No verão ocorrem as chamadas chuvas torrenciais ou catastróficas, que proporcionam um grande carreamento de material já previamente processado, oriundo do solo marginal ao riacho. Na primavera já ocorreu uma lavagem superficial, sendo que no verão ocorre um carreamento mais intenso deste folhiço acumulado no solo, mais fragmentado e particulado. A maior presença de grupos de Chironomidae semi-terrestres no folhiço do riacho durante a primavera e o verão seria um indicativo da entrada de matéria orgânica oriunda das margens. No inverno, a fragmentação do material seria uma consequiência do processamento do mesmo no próprio riacho, já que a vazão baixa e a presença de madeira como armadilha aumentariam o tempo de retenção e, conseqüentemente, de decomposição. Covich (1988) aponta que o padrão de entrada de folhiço em bacias tropicais é geralmente afetado pela sazonalidade das chuvas, e que a imprevisibilidade das tempestades (causadoras de "chuva de detritos" para o sistema) torna complicada a visão de um padrão de entrada anual de folhiço.

No outono foram observados o menor peso e a menor quantidade total de componentes. Os depósitos de folhiço encontraram-se menores principalmente devido à alta vazão do riacho observada, a maior dentre as estações estudadas. Esta maior vazão foi conseqüência do aumento da captação de água pela bacia devido as chuvas contínuas (porém não torrenciais e pontuais como no verão).

O outono apresentou características opostas ao inverno não só com relação ao menor peso do substrato e a maior vazão, mas com relação a maior densidade de larvas. Como a densidade foi calculada em número de indivíduos por grama de peso seco do folhiço, uma explicação direta seria que o menor peso do folhiço no outono resultaria em uma maior densidade, enquanto que o maior peso no inverno ocasionaria uma menor densidade. Porém, duas hipóteses poderiam ser levantadas. Uma delas seria com relação a qualidade do recurso; no inverno, o folhiço é principalmente composto por madeira, cujo valor nutricional como recurso é menor em comparação as folhas e demais componentes. Apenas alguns grupos de Chironomidae são capazes de se alimentar diretamente de madeira, e esta menor existência de xilófagos reflete a baixa qualidade do recurso (Berg 1995). Assim, a menor densidade de larvas no inverno poderia ser um indicativo da baixa qualidade do substrato como fonte de alimento. Uma outra hipótese seria a competição e a existência de predadores por outros grupos de insetos aquáticos. Apesar de Chironomidae ter apresentado a menor densidade no inverno, os demais grupos de insetos aquáticos habitantes do folhiço submerso no riacho mostraram maiores densidades nesta estação (observação pessoal), o que poderia significar uma maior competição por espaço e recursos e um aumento dos predadores de larvas.

Houve variação na estrutura da fauna de Chironomidae entre as estações do ano. A maior participação de Chironominae em depósitos de folhiço em riachos na Mata Atlântica vem sendo observada em trabalhos anteriores (Sanseverino et al. 1998; Sanseverino \& Nessimian 2001). Ashe et al. (1987) mencionam que a maioria dos gêneros de Chironominae ocorre em ambientes de água parada, e que quando ocorrem em águas correntes geralmente são encontrados em rios de menor correnteza ou, no caso de rápida correnteza, em áreas onde a velocidade da água é menor (zonas de depósito). Por outro lado, Orthocladiinae são considerados primariamente lóticos (Coffman \& Ferrington 1984, 1996), sendo mais freqüentes em áreas onde a velocidade da corrente é maior. Desta forma sua maior participação no outono poderia ser explicada, já que coincidiu com o período de maior vazão do riacho.

Os grupos mais comuns foram Lauterborniella, Phaenopsectra, Polypedilum, Tanytarsus (Chironominae), Corynoneura e Nanocladius (Orthocladiinae). As larvas de Lauterborniella são construtoras de tubos móveis (Coffman \& Ferrington 1984, 1996), sendo o grupo com maior número de indivíduos neste estudo, podendo ser caracterizadas como habitantes do folhiço submerso. Phaenopsectra é reportada em poças temporárias (Grodhaus 1987) e habitando áreas de depósito (remansos) com presença de silte, areia e folhiço (Ferrington et al. 1995). Polypedilum e Tanytarsus são grupos amplamente distribuídos, ocorrendo em vários tipos de hábitat sob diferentes condições ambientais (Pinder \& Reiss 1983; Epler 1995). Larvas de Corynoneura também são habitantes de diversos tipos de substrato, principalmente em áreas de depósito, e Nanocladius são habitantes de áreas de erosão (Coffman \& Ferrington 1984, 1996).

O número de larvas de Lopescladius encontrado no outono foi o maior, estando este grupo nas demais estações do ano ausente ou com poucas larvas. Ainda, o outono foi a única estação em que foram encontradas larvas de Cryptochironomus e do complexo Harnischia gênero 1. Estes resultados podem ser uma conseqüência da maior vazão observada neste período, ocasionando alguma mistura entre o fundo arenoso e o bolsão de folhiço. Lopescladius, Cryptochironomus e complexo Harnischia gênero 1 são caracterizados como habitantes de sedimento (areia) em áreas de depósito (Sanseverino \& Nessimian 2001). Epler (1995) menciona que Cryptochironomus e Lopescladius são encontrados no fundo de rios e riachos, e Pinder (1995) relata que vários gêneros do complexo Harnischia são apontados como característicos de substrato arenoso.

Segundo Epler (1995), Georthocladius é encontrado em solos úmidos de floresta, fazendo parte do grupo de Orthocladiinae considerado semi-terrestre. Neste trabalho foi encontrado um grupo próximo a Georthocladius (aff. Georthocladius), com maiores participações na primavera e no verão, estando ausente no outono e com apenas um indivíduo no inverno. Segundo Pinder (1995), as larvas consideradas semi-terrestres (ou semi-aquáticas) vivem no solo 
úmido ou na vegetação. Assim, a presença deste grupo no folhiço submerso poderia ser devida à ocorrência das chuvas na primavera e verão, carreando para o riacho o folhiço depositado no solo marginal onde estariam estas larvas.

De acordo com os resultados da CCA, os três primeiros eixos contribuíram com $31 \%$ da variância observada, e a correlação espécie-ambiente foi alta nestes três eixos. Aparentemente, as variáveis ambientais incluídas na análise explicaram as principais variações na fauna de Chironomidae dos depósitos de folhiço submerso. Os coeficientes canônicos e de correlação indicaram que as variáveis folhas e madeira foram mais relevantes na composição da comunidade de Chironomidae no eixo 1, a vazão no 2, e folhas, madeira, peso da matéria orgânica e fragmentação do folhiço no 3, sendo que os dois primeiros eixos contribuíram juntos com $25,3 \%$ da variância.

O primeiro eixo representa um gradiente de matéria orgânica do folhiço, onde as amostras com maior peso de matéria orgânica foram as que apresentaram maiores quantidades de madeira e menores de folhas, enquanto que as de menor peso apresentaram maiores quantidades de folhas e menores de madeira. Algumas exceções podem ser observadas, como a amostra P2 da primavera, a qual apresentou a maior quantidade de folhas e pouca madeira, mas teve o segundo maior peso de matéria orgânica. A quantidade de madeira e de folhas foi um importante fator para a fauna de Chironomidae. O vetor da variável madeira ordenou amostras com maiores quantidades de madeira (I4, P3, I5) até amostras com menores quantidades de madeira (O3, P2), enquanto que o eixo de folhas exibiu um gradiente, da direita para a esquerda, de amostras com menores quantidades de folhas (P3, O5, O4) até amostras com maiores quantidades de folhas (V3, P4, P2).

O segundo eixo representa um gradiente de vazão do riacho. $\mathrm{O}$ vetor que representa a variável vazão no diagrama mostrou um gradiente de amostras coletadas na estação com a menor vazão, o inverno, até amostras coletadas no outono, com a maior vazão. Esse eixo apresenta bem este gradiente de valores crescentes ao longo das estações do ano.

A partir das posições das espécies e amostras no diagrama de ordenação da CCA, pode-se deduzir que Xestochironomus e Phaenopsectra foram mais abundantes nas amostras com maiores quantidades de madeira e menores de folhas. Estes dois gêneros tiveram maior participação no inverno, onde as amostras de folhiço mostraram estas características. Além disso, larvas de Xestochironomus são minadoras de madeira submersa (Borkent 1984; Epler 2001), enquanto que as de Phaenopsectra foram muitas vezes observadas em detrito aderido a pequenos pedaços de madeira do folhiço. Os gêneros Lopescladius e Parametriocnemus tiveram suas maiores abundâncias nas amostras de outono (maior vazão), enquanto que Corynoneura e Nanocladius ocorreram em maior número em amostras com maior quantidade de folhas.

Embora tenha ocorrido nítida variação na estrutura da comunidade de Chironomidae durante o período estudado, deve-se ressaltar que estes resultados referem-se a coletas realizadas em um determinado mês dentro das estações do ano, e que previsões acerca dos padrões devem ser feitas levando em consideração a dinâmica do sistema e a biologia das espécies. Resh \& Rosenberg (1989) chamam atenção ao fato de que as variações espaciais e temporais em insetos aquáticos ocorrem concomitantemente, mostrando que emergência, alimentação, crescimento, movimentos e migrações estão entre as causas comuns da variabilidade na riqueza de espécies, densidade e biomassa.

Cummins \& Lauff (1969) investigaram preferências de microhábitat para dez espécies de macroinvertebrados bentônicos, concluindo que enquanto a correnteza, temperatura ou concentração de um fator químico pode limitar as extensões gerais de tolerância de hábitat (macrodistribuição), o tamanho de partícula do substrato ou a oferta de alimento provavelmente exerceria influências na microdistribuição primária.

Segundo Schmid (1992), fatores que afetam indivíduos ou grupos de Chironomidae podem contribuir para padrões dinâmicos espaciais e temporais da distribuição das larvas. Fatores físicos podem mudar a disponibilidade de microhábitats para as larvas, o que poderá se refletir em uma segregação espacial flutuante.

Agradecimentos. Os autores agradecem ao Dr. Friedrich Reiss (in memorian) pela ajuda na identificação taxonômica e ao Museu de Zoologia de Munique (ZSM) pela consulta de material e auxílio. Agradecemos ao CNPq, a Capes e ao PPGE-UFRJ pelas bolsas, subvenção e apoio concedidos

\section{REFERÊNCIAS}

Ashe, P.; D. A. Murray \& F. Reiss. 1987. The zoogeographical distribution of Chironomidae (Insecta: Diptera). Annales de Limnologie 23: 27-60.

Benfield, E. F. 1997. Comparison of litterfall input to streams. Journal of the North American Benthological Society 16: 104-108. Berg, M. B. 1995. Larval food and feeding behaviour, p. 136-168. In: P. D. Armitage; P. S. Cranston \& L. C. V. Pinder (eds.). The Chironomidae. Biology and ecology of non-biting midges. London, Chapman \& Hall, $584 \mathrm{p}$.

Bilby, R. E. \& G. E. Likens. 1980. Importance of organic debris dams in the structure and function of stream ecosystems. Ecology 61: 1107-1113.

Borkent, A. 1984. The systematics and phylogeny of the Stenochironomus complex (Xestochironomus, Harrisius, and Stenochironomus) (Diptera: Chironomidae). Memoirs of the Entomological Society of Canada 128: 1-269.

Cheng, L. \& J. D. Collins. 1980. Observations on behavior, emergence and reproduction of the marine midges Pontomyia (Diptera: Chironomidae). Marine Biology 58: 1-5.

Coffman, W. P. \& L. C. Ferrington Jr. 1984. Chironomidae, p. 551652. In: R. W. Merritt \& K. W. Cummins (eds.). An introduction to the aquatic insects of North America. Dubuque, Kendall Hunt Publishing Co., 2.ed., 722 p.

Coffman, W. P. \& L. C. Ferrington Jr. 1996. Chironomidae, p. 635754. In: R. W. Merritt \& K. W. Cummins (eds.). An introduction to the aquatic insects of North America. Kendall Hunt Publishing Co., Dubuque, 3.ed., xiii +862 p.

Covich, A. P. 1988. Geographical and historical comparisons of neotropical streams: biotic diversity and detrital processing in highly variable habitats. Journal of the North American Benthological Society 7: 361-386. 
Cranston, P. S.; D. R. Oliver \& O. A. Sæther. 1983. The larvae of Orthocladiinae (Diptera: Chironomidae) of the Holarctic Region Keys and diagnoses, p. 149-291. In: T. Wiederholm (ed.). Chironomidae of the Holarctic region - keys and diagnoses. Part 1 - Larvae. Motala, Entomologica Scandinavica Supplement $19,457 \mathrm{p}$.

Cummins, K. W. \& G. H. Lauff. 1969. The influence of substrate particle size on the microdistribution of stream macrobenthos. Hydrobiologia 34: 145-181.

Epler, J. H. 1995. Identification manual for the larval Chironomidae of Florida. Revised edition. Tallahassee, Final Rep. DEP Contr. No.WM579, St. Fla, Dep. Envir. Protect., Div. Wat. Facilities, 319 p.

Epler, J. H. 2001. Identification manual for the larval Chironomidae (Diptera) of North and South Carolina. North Carolina, North Carolina Dep. Envir. Natural Resources, Div. Water Quality. http://www.esb.enr.state.nc.us/BAUwww/Chironomid.htm

Ferrington, Jr. L. C.; R. G. Kavanaugh; F. J. Schmidt \& J. L. Kavanaugh. 1995. Habitat separation among Chironomidae (Diptera) in Big Springs. Journal of the Kansas Entomological Society 68: $152-165$.

Graça, M. A. S. 2001. The role of invertebrates on leaf litter decomposition in streams - a review. International Review of Hydrobiology 86: 383-393.

Grodhaus, G. 1987. Phaenopsectra mortensoni n. sp. and its relationship to other Chironomidae (Diptera) of temporary pools. Entomologica Scandinavica Supplement 29: 137-145.

Kobayashi, S. \& T. Kagaya. 2002. Differences in litter characteristics and macroinvertebrate assemblages between litter patches in pools and riffles in a headwater stream. Limnology 3: 37-42.

McCune, B. 1997. Influence of noisy environmental data on canonical correspondence analysis. Ecology 78: 2617-2623.

McCune, B. \& M. J. Mefford. 1999. PC-ORD for Windows version 4.14. Multivariate analysis of ecological data. $\mathrm{MjM}$ Software, Gleneden Beach, Oregon, 1 CD.

Pinder, L. C. V. 1995. The habitats of chironomid larvae, p. 107-135. In: P. D. Armitage; P. S. Cranston \& L. C. V. Pinder (eds.). The Chironomidae. Biology and ecology of non-biting midges. London, Chapman \& Hall, 584 p.

Pinder, L. C. V. \& F. Reiss. 1983. The larvae of Chironominae (Diptera: Chironomidae) of the Holarctic Region - Keys and diagnoses, p. 293-435. In: T. Wiederholm (ed.). Chironomidae of the Holarctic region - keys and diagnoses. Part 1 - Larvae. Motala, Entomologica Scandinavica Supplement 19, 457 p.

Pozo, J.; E. Gonzales; J. R. Diez; J. Molinero \& A. Elosegui. 1997. Inputs of particulate organic matter to streams with different riparian vegetation. Journal of the North American Benthological Society 16: 602-611.

Rae, J. G. 2004. The colonization response of lotic chironomid larvae to substrate size and heterogeneity. Hydrobiologia 524: 115124.

Resh, V. H. \& D. M. Rosenberg. 1989. Spatial-temporal variability and the study of aquatic insects. Canadian Entomologist 121: 941963.

Sanseverino, A. M. \& J. L. Nessimian. 1998. Habitat preferences of Chironomidae larvae in an upland stream of Atlantic Forest, Rio de Janeiro State, Brazil. Verhandlungen der Internationalen Vereinigung für Theoretische und Angewandte Limnologie 26: $2141-2144$.

Sanseverino, A. M. \& J. L. Nessimian. 2001. Hábitats de larvas de Chironomidae (Insecta, Diptera) em riachos de Mata Atlântica no Estado do Rio de Janeiro. Acta Limnologica Brasiliensia 13: 29-38.

Sanseverino, A. M.; J. L. Nessimian \& A. L. H. Oliveira. 1998. A fauna de Chironomidae (Insecta: Diptera) em diferentes biótopos aquáticos na Serra do Subaio (Teresópolis, RJ). Oecologia Brasiliensis 5: 253-263.

Schmid, P. E. 1992. Population dynamics and resource utilization by larval Chironomidae (Diptera) in a backwater area of the River Danube. Freshwater Biology 28: 111-127.

Ter Braak, C. J. F. 1986. Canonical Correspondence Analysis: a new eigenvector technique for multivariate direct gradient analysis. Ecology 67: 1167-1179.

Trixinho-Strixino, S. \& G. Strixino. 1995. Larvas de Chironomidae (Diptera) do Estado de São Paulo: guia de identificação e diagnose dos gêneros. São Carlos, SP: PPG-ERN/UFSCAR, 229p.

Vannote, R. L.; G. W. Minshall; K. W. Cummins; J. R. Sedell \& C. E. Cushing. 1980. The river continuum concept. Canadian Journal of Fisheries and Aquatic Sciences 37: 130-137.

Vinson, M. R. \& C. P. Hawkins. 1998. Biodiversity of stream insects: variation at local, basin and regional scales. Annual Review of Entomology 43: 271-93.

Walker, I. 1987. The biology of streams as part of Amazonian forest ecology. Experientia 43: 279-287.

Walker, I. 1992. The benthic litter habitat with its sediments load in the inundation forest of the Central Amazonian blackwater river Tarumã Mirim. Amazoniana 12: 143-153.

Wallace J. B.; S. L. Eggert; J. L. Meyer \& J. R. Webster. 1997. Multiple trophic levels of a forest stream linked to terrestrial litter inputs. Science 277: 102-104.

Wallace J. B.; S. L. Eggert; J. L. Meyer \& J. R. Webster. 1999. Effects of resource limitation on a detrital-based ecosystem. Ecological Monographs 69: 409-442.

Ward, J. V. 1992. Aquatic insect ecology I- Biology and habitat. New York, John Wiley \& Sons, Inc., 437 p.

Webster, J. R \& D. J. D'Angelo. 1997. A regional analysis of the physical characteristics of streams. Journal of the North American Benthological Society 16: 87-95.

Recebido em 25/04/2007; aceito em 19/10/2007 